Characterization of a high-temperature superconducting conductor on round core cables in magnetic fields up to $20 \mathrm{~T}$

This article has been downloaded from IOPscience. Please scroll down to see the full text article.

2013 Supercond. Sci. Technol. 26045005

(http://iopscience.iop.org/0953-2048/26/4/045005)

View the table of contents for this issue, or go to the journal homepage for more

Download details:

IP Address: 132.163.52.122

The article was downloaded on 14/02/2013 at 17:55

Please note that terms and conditions apply. 


\title{
Characterization of a high-temperature superconducting conductor on round core cables in magnetic fields up to $20 \mathrm{~T}^{*}$
}

\author{
D C van der Laan ${ }^{1,2,3}$, P D Noyes ${ }^{4}$, G E Miller ${ }^{4}$, H W Weijers ${ }^{4}$ and \\ G P Willering ${ }^{5}$ \\ ${ }^{1}$ Advanced Conductor Technologies LLC, Boulder, CO 80301, USA \\ 2 Department of Physics, University of Colorado, Boulder, CO 80309, USA \\ ${ }^{3}$ National Institute of Standards and Technology, Boulder, CO 80305, USA \\ ${ }^{4}$ National High Magnetic Field Laboratory, Tallahassee, FL 32310, USA \\ ${ }^{5}$ CERN, CH-1211 Genève 23, Switzerland
}

E-mail:danko@advancedconductor.com

Received 29 November 2012, in final form 22 January 2013

Published 13 February 2013

Online at stacks.iop.org/SUST/26/045005

\begin{abstract}
The next generation of high-field magnets that will operate at magnetic fields substantially above $20 \mathrm{~T}$, or at temperatures substantially above $4.2 \mathrm{~K}$, requires high-temperature superconductors (HTS). Conductor on round core (CORC) cables, in which RE- $\mathrm{Ba}_{2} \mathrm{Cu}_{3} \mathrm{O}_{7-\delta}$ $(\mathrm{RE}=$ rare earth) $(\mathrm{REBCO})$ coated conductors are wound in a helical fashion on a flexible core, are a practical and versatile HTS cable option for low-inductance, high-field magnets. We performed the first tests of CORC magnet cables in liquid helium in magnetic fields of up to $20 \mathrm{~T}$. A record critical current $I_{\mathrm{c}}$ of $5021 \mathrm{~A}$ was measured at $4.2 \mathrm{~K}$ and $19 \mathrm{~T}$. In a cable with an outer diameter of $7.5 \mathrm{~mm}$, this value corresponds to an engineering current density $J_{\mathrm{e}}$ of $114 \mathrm{~A} \mathrm{~mm}^{-2}$, the highest $J_{\mathrm{e}}$ ever reported for a superconducting cable at such high magnetic fields. Additionally, the first magnet wound from an HTS cable was constructed from a $6 \mathrm{~m}$-long CORC cable. The 12-turn, double-layer magnet had an inner diameter of $9 \mathrm{~cm}$ and was tested in a magnetic field of $20 \mathrm{~T}$, at which it had an $I_{\mathrm{c}}$ of $1966 \mathrm{~A}$. The cables were quenched repetitively without degradation during the measurements, demonstrating the feasibility of HTS CORC cables for use in high-field magnet applications.
\end{abstract}

(Some figures may appear in colour only in the online journal)

\section{Introduction}

Low-temperature superconductors (LTS) are limited to magnetic fields lower than 20-22 $\mathrm{T}$ in liquid helium due to their limited upper critical field $B_{\mathrm{c} 2}$, which is about $27 \mathrm{~T}$ for $\mathrm{Nb}_{3} \mathrm{Sn}$ [1]. There is a growing need for magnets that operate at magnetic fields that exceed $20 \mathrm{~T}$, or that operate at temperatures above the boiling temperature of liquid helium. These magnets include the next generation high-energy physics magnets [2], magnets for fusion experiments [3], superconducting magnetic energy storage (SMES) [4], and

\footnotetext{
* Partial contribution of NIST, not subject to US copyright.
}

other science magnets [5]. High-temperature superconductors are the only feasible materials for use in these magnets due to their very high $B_{\mathrm{c} 2}$ values, which are expected to exceed $100 \mathrm{~T}$ at $4.2 \mathrm{~K}$ [1]. High-field magnet research is currently focused on two HTS materials: $\mathrm{Bi}_{2} \mathrm{Sr}_{2} \mathrm{CaCu}_{2} \mathrm{O}_{8}$ (Bi-2212) wires and REBCO coated conductors. REBCO coated conductors are especially attractive candidates because of their high critical temperature of $92 \mathrm{~K}$, and their high mechanical strength. Several high-field magnet programs utilizing REBCO coated conductors are underway; for example, a $32 \mathrm{~T}$, all-superconducting magnet at the National High Magnetic Field Laboratory (NHMFL), and a toroid SMES at Brookhaven National Laboratory that will operate 
at a field of between 25 and $30 \mathrm{~T}$ [4]. These high-inductance magnets are wound from single-tape conductors that carry currents of no more than a few hundred amperes at their operating field and at $4.2 \mathrm{~K}$. The single-tape windings are subject to stringent conductor requirements with respect to conductor homogeneity to prevent local hotspots in the magnet. The high magnet inductance makes quench protection very challenging because of the very high voltages that could develop during a quench.

Fast-ramping magnets for high-energy physics and fusion applications require a low inductance and therefore need high-current windings. Accelerator magnets that are currently operated at the large Hadron collider (LHC) at CERN operate at a winding current of $11850 \mathrm{~A}$ and a $J_{\mathrm{e}}$ of about 300-400 A mm $\mathrm{m}^{-2}$ at $8.3 \mathrm{~T}$. The central solenoid in the international thermal-nuclear experimental reactor (ITER) is designed to operate at a winding current of $46000 \mathrm{~A}$ and a winding current density $J_{\mathrm{w}}$ of about $19 \mathrm{~A} \mathrm{~mm}^{-2}$ at $13 \mathrm{~T}$ [6]. $J_{\mathrm{w}}$ is the current density in the overall magnet windings, taking structural materials and voids between the round windings into account. One of the main challenges for HTS to be utilized in low-inductance magnet applications is for them to be bundled into high-current cables. To be feasible for high-field magnet applications, these cables need to be relatively flexible, have a high cable current of at least several kiloamperes, and a $J_{\mathrm{e}}$ of at least $50 \mathrm{~A} \mathrm{~mm}^{-2}$ at the operating field and temperature.

Several HTS cabling methods are being explored; for example, Bi-2212 wires have been cabled into a Rutherford configuration [7] and a cable current of $1700 \mathrm{~A}$ at $15 \mathrm{~T}$ has been predicted [8]. There are still major challenges that need to be overcome with $\mathrm{Bi}-2212$ wires before they become a viable option for high-field magnets. These challenges include raising the critical current density $J_{\mathrm{c}}$, optimizing the conductor processing conditions to reduce leakage and bubble formation [9], and significantly raising their mechanical strength [10].

Three approaches are being pursued to cable REBCO coated conductors into a configuration applicable to high-field magnets. Patterned REBCO coated conductors are assembled into a Roebel bar configuration [11] with a demonstrated critical current at $77 \mathrm{~K}$ of several kiloamperes in selffield [12]. The Twisted Stack approach uses multiple REBCO coated conductors stacked into a rectangular configuration and then twisted [13]. A critical current of $1530 \mathrm{~A}$ in self-field has been demonstrated in this cable configuration at $77 \mathrm{~K}$ [14]. These two cable configurations have the disadvantage that the cables are not very flexible and that current sharing between individual tapes in the cable is limited. Initial data on the in-field performance of these cables has been presented, but no data have yet been published. Additionally, longitudinal defects are frequently present in REBCO coated conductors $[15,16]$, which severely limit the performance of Roebel cables because the patterning of the strands forces the current to cross these defects.

Advanced Conductor Technologies LLC is currently developing CORC cables for power transmission and high-field magnet applications [17]. We have demonstrated that CORC cables, in which multiple coated conductors are wound in a helical fashion on a round former, are relatively flexible and can potentially be wound into magnets that require tight cable bends [18, 19]. The high level of elasticity of REBCO coated conductors, especially under axial compressive strain [20], enables them to be wound on relatively small formers of only several millimeters in diameter without experiencing irreversible degradation. Additionally, the anisotropic nature of the reversible strain effect in REBCO coated conductors [16], in combination with the conductor winding angle of between $30^{\circ}$ and $60^{\circ}$ in CORC cables, results in only a minimal reversible reduction of the conductor performance due to both winding and operating strains. Several high-current CORC cables have been demonstrated, the most prominent cable having an $I_{\mathrm{c}}$ of $7651 \mathrm{~A}$ at $76 \mathrm{~K}$ in a cable with outer diameter of only $10 \mathrm{~mm}[21]$.

Here, we present the results of the first measurements of CORC cables at high magnetic field up to $20 \mathrm{~T}$, which were performed at the user facility of the NHMFL. An insert to provide the CORC cables with the mechanical support needed to withstand the Lorentz forces generated by multi-kiloampere currents in high magnetic fields was developed for the $20 \mathrm{~cm}$ bore resistive magnet at the NHMFL. Five CORC cables, one wound into a small magnet, were successfully tested and demonstrate the feasibility of high- $J_{\mathrm{e}}$ CORC cables for low-inductance magnet applications.

\section{Experimental details}

\subsection{Conductor on round core cables}

A total of five CORC cable samples were prepared for testing in a background magnetic field of up to $20 \mathrm{~T}$. An overview of the different cables, including information on the former material and the outer diameter of the cables, the number of tapes and layers in the cables, and the details of the tapes with which the cables were wound, is provided in table 1. The cables were assembled from $4 \mathrm{~mm}$ wide REBCO coated conductors from SuperPower, Inc., consisting of a $50 \mu \mathrm{m}$ thick Hastelloy C-276 substrate, a $1 \mu \mathrm{m}$ thick superconducting layer, and a $20 \mu \mathrm{m}$ thick surround plated copper layer. Some of the cables were constructed from coated conductors that contained advanced pinning centers through nanoparticles and are designated AP for 'advanced pinning'. Coated conductors that did not contain additional pinning centers are designed ST for 'standard'.

Cable CORC-1 was constructed from a $5.0 \mathrm{~mm}$ diameter solid aluminum former and 6 ST coated conductors. The former was pre-shaped into a $11 \mathrm{~cm}$ diameter loop to fit the cable support structure (see section 2.2) and to ensure minimum cable degradation due to cable bending. Additional mechanical support was provided by filling the cable with 51 wt $\%$ In-32.5 wt $\% \mathrm{Bi}-16.5$ wt $\% \mathrm{Sn}$ solder after winding. The cable was insulated with a layer of polyamide tape.

Cable CORC-2 was prepared by use of a flexible, stranded-copper, insulated former that had an outer diameter of $5.5 \mathrm{~mm}$. The $1.2 \mathrm{~m}$-long, straight cable consisted of $12 \mathrm{ST}$ 
Table 1. CORC cable specifications.

\begin{tabular}{llllll}
\hline Sample \# & Former/diameter $(\mathrm{mm})$ & $\begin{array}{l}\text { \# of tapes/\# } \\
\text { of layers }\end{array}$ & $\begin{array}{l}\text { Current } \\
\text { capacity }\end{array}$ & $\begin{array}{l}\text { Conductor type/I } \\
(76 \mathrm{~K}, 0 \mathrm{~T})(\mathrm{A})\end{array}$ & $\begin{array}{l}\text { Cable outer } \\
\text { diameter }(\mathrm{mm})\end{array}$ \\
\hline CORC-1 & Solid Al/5.0 & $6 / 2$ & Low & ST/120 & 5.5 \\
CORC-2 & Insulated stranded Cu/5.5 & $12 / 4$ & Low & ST/120 & 6.5 \\
CORC-3 & Insulated stranded Cu/4.0 & $40 / 13$ & High & 9 ST, 31 AP/130, 110 & 7.5 \\
CORC-4 & Insulated stranded Cu/3.2 & $52 / 17$ & High & AP/120 & 7.5 \\
CORC-5 & Insulated stranded Cu/5.5 & $20 / 6$ & High & 10 ST, 10 AP/130, 110 & 7.0 \\
\hline
\end{tabular}

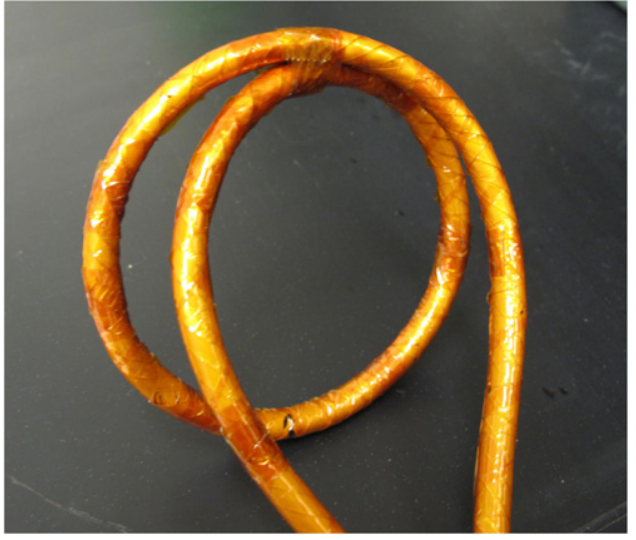

Figure 1. Cable CORC-2 after it was bent into a $12 \mathrm{~cm}$ diameter loop.

tapes that were wound into 4 layers, and an outer layer of polyamide insulation. The cable was bent into the $11 \mathrm{~cm}$ diameter loop after it was wound (see figure 1).

Cable CORC-3 was constructed by use of a flexible, insulated, stranded-copper former with a diameter of only $4.0 \mathrm{~mm}$. The initial 4 layers in the cable were wound from 9 ST coated conductors, on top of which an additional 31 AP coated conductors were wound into 8 layers. The cable consisted of a total of 40 coated conductors in 13 layers and had an outer diameter of $7.5 \mathrm{~mm}$. Cable CORC-4 contained 52 AP conductors that were wound into 17 layers onto a $3.2 \mathrm{~mm}$ diameter former. The cable had an outer diameter of $7.5 \mathrm{~mm}$.

Cable CORC-5 was a cable in which $10 \mathrm{AP}$ and $10 \mathrm{ST}$ coated conductors were wound into 6 layers onto a flexible, insulated, stranded, copper former with a diameter of $5.5 \mathrm{~mm}$. The $6 \mathrm{~m}$-long cable was wound onto an aluminum cylinder, forming a two-layer, 12-turn magnet. The magnet was $4.5 \mathrm{~cm}$ in height, had an inner diameter of $9 \mathrm{~cm}$ and an outer diameter of $12 \mathrm{~cm}$. Figure 2 shows the inner 6 turns of the magnet after they were wound onto the aluminum cylinder. The magnet was filled with epoxy after it was inserted into the support structure.

\subsection{Cable support structure}

Cables CORC-1 to CORC-4 were wound into a 1.5-turn loop with a $11 \mathrm{~cm}$ diameter (see figure 1) to ensure that the orientation of the external magnetic field was normal to the cable. A structure was developed to support the CORC cables against Lorentz forces of up to $40 \mathrm{kN}$ per turn at $19 \mathrm{~T}$

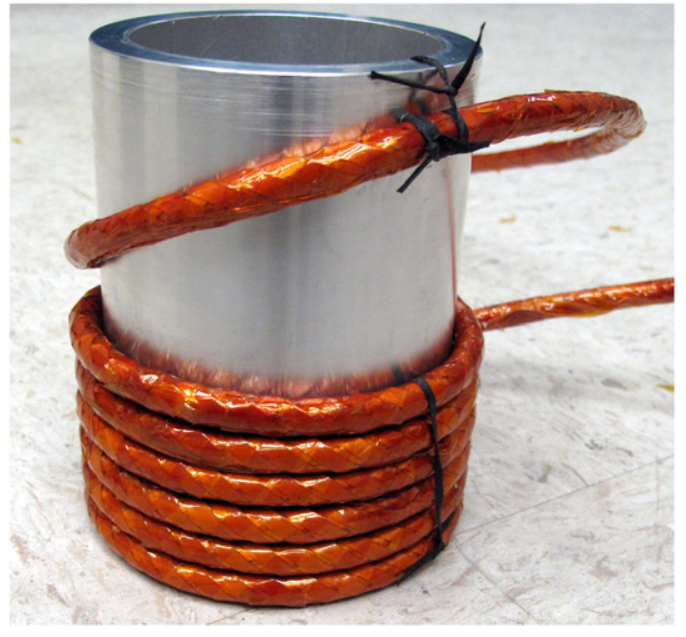

Figure 2. The 6 turns of the inner layer of the magnet that was wound from sample CORC-5.

and a sample current of 6000 A. The 1.5-turn cable loops were inserted into an aluminum cup located at the bottom of the support structure, which was then filled with epoxy (see figure 3(a)). The cable sections close to the terminals were supported by a G-10 cable spacer (see figure 3(a)). The cable, with its support structure, was bolted to the inside of an aluminum tube (figure 3(b)) located at the tail end of the insert structure (figure 3(c)) and was connected to the vapor-cooled current leads that were rated at $7500 \mathrm{~A}$.

\section{Results}

Several CORC cables were studied in a background field as high as $19.8 \mathrm{~T}$. These cables included two low-current CORC cables that had an $I_{\mathrm{c}}$ of less than $1000 \mathrm{~A}$ at $4.2 \mathrm{~K}$ and $19.8 \mathrm{~T}$, and three high-current CORC cables that had an $I_{\mathrm{c}}$ far exceeding $1000 \mathrm{~A}$ under these conditions. Table 2 lists the performance of the five HTS CORC cables together with the performance of LTS cables used in some of the main low-inductance magnets that are either in operation or are being developed.

\subsection{Low-current CORC cable tests}

Measurements of cable CORC-1 at $76 \mathrm{~K}$ in self-field were conducted at NIST before the cable was tested at the NHMFL. Throughout this paper, the critical current is defined at an electric field criterion of $1 \mu \mathrm{V} \mathrm{cm}{ }^{-1}$, with the distance 
Table 2. Performance of HTS CORC cables and LTS magnet cables.

\begin{tabular}{lllllll}
\hline Cable & $I_{\mathrm{c}}(19.8 \mathrm{~T})(\mathrm{A})$ & $I_{\mathrm{c}}(12 \mathrm{~T})(\mathrm{A})$ & $\begin{array}{l}J_{\mathrm{e}}(19.8 \mathrm{~T}) \\
\left(\mathrm{A} \mathrm{mm}^{-2}\right)\end{array}$ & $\begin{array}{l}J_{\mathrm{e}}(12 \mathrm{~T}) \\
\left(\mathrm{A} \mathrm{mm}^{-2}\right)\end{array}$ & $\begin{array}{l}J_{\mathrm{w}}(19.8 \mathrm{~T}) \\
\left(\mathrm{A} \mathrm{mm}^{-2}\right)\end{array}$ & $\begin{array}{l}J_{\mathrm{w}}(12 \mathrm{~T}) \\
\left(\mathrm{A} \mathrm{mm} \mathrm{mm}^{-2}\right)\end{array}$ \\
\hline CORC-1 & 526 & 686 & 22 & 29 & 17 & 23 \\
CORC-2 & 877 & 1120 & 26 & 33 & 21 & 27 \\
CORC-3 & 3327 & 4422 & 76 & 101 & 60 & 80 \\
CORC-4 & $5021(19 \mathrm{~T})$ & - & $114(19 \mathrm{~T})$ & - & $89(19 \mathrm{~T})$ & -54 \\
CORC-5 & 1966 & 2657 & 51 & 69 & 40 & $19(13 \mathrm{~T})$ \\
$\begin{array}{l}\text { ITER central solenoid } \\
\text { (under development) }\end{array}$ & - & $46000(13 \mathrm{~T})$ & - & & - & $40(15.3 \mathrm{~T})$ \\
$\begin{array}{l}\text { NHMFL 45 T hybrid } \\
\text { LTS outsert [22] }\end{array}$ & - & $10000(15.3 \mathrm{~T})$ & - & $50(15.3 \mathrm{~T})$ & - & \\
\hline
\end{tabular}

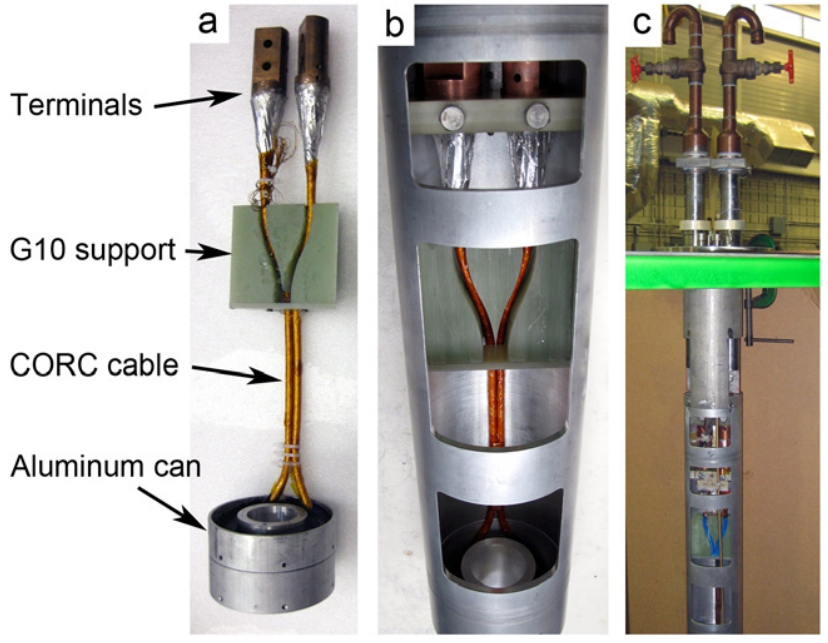

Figure 3. (a) CORC cable with local reinforcement provided by the epoxy-filled aluminum cup and the G-10 structure near the cable ends. (b) Cable inserted into the lower part of the support structure. (c) Magnet insert containing the cable sample and vapor-cooled current leads.

measured along the tapes in the cable, unless stated otherwise. The $n$-value, which is an indication of the steepness of the superconducting transition at an electric field of $1 \mathrm{mV} \mathrm{cm}^{-1}$, was 13.5. The critical current was determined by means of a set of voltage contacts that were located on the copper terminals of the cable and subtracting the resistive voltage from the overall voltage. This resulted in an $I_{\mathrm{c}}$ of $593 \mathrm{~A}$ and a total contact resistance between the copper cable terminals and the superconducting tapes of $75 \mathrm{n} \Omega$ at $76 \mathrm{~K}$. The method for determining $I_{\mathrm{c}}$ from the voltage across the cable terminals is used throughout this paper unless stated otherwise. In some cases, a voltage tap across a single tape is used to determine the cable $I_{\mathrm{c}}$, but this method relies on a uniform current distribution, and an error will occur if the joint resistance, and therefore current distribution, is not equal for all tapes. All measurements of the cables were performed up to a current at which the cables quenched. The cables were protected with a quench protection circuit that caused the sample current to cut off when the voltage at the cable terminals exceeded $2 \mathrm{mV}$.

The cable $I_{\mathrm{c}}$ of cable CORC- 1 was measured as a function of applied magnetic field at $4.2 \mathrm{~K}$ in the resistive magnet at the NHMFL (it was $526 \mathrm{~A}$ at $19.8 \mathrm{~T}$ ). The joint resistance of sample CORC-1 at $4.2 \mathrm{~K}$ was $25 \mathrm{n} \Omega$ for both joints combined.

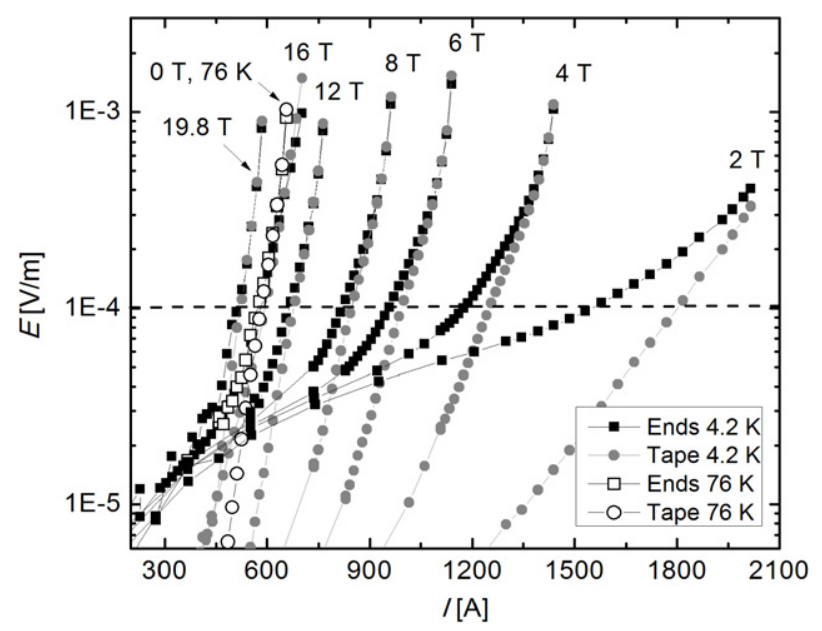

Figure 4. $E-I$ characteristics of cable CORC-1, measured with two sets of voltage contacts as a function of magnetic field at $4.2 \mathrm{~K}$. One set was located on the copper terminal (squares) and one set was located on one of the tapes in the outer layer of the cable (circles). Included in the figure are the $E-I$ curves that were measured at $76 \mathrm{~K}$ in self-field (open symbols). The dashed line indicates the electric field criterion of $1 \mu \mathrm{V} \mathrm{cm}^{-1}$.

Since the magnetic field was only applied to the 1.5 turns, the effective tape length between the voltage contacts was reduced from about $1.5 \mathrm{~m}$ in self-field to only $0.4 \mathrm{~m}$ with applied field.

The electric field versus current $(E-I)$ characteristics of cable CORC-1, measured with two sets of voltage contacts, are shown in figure 4 for different magnetic fields at $4.2 \mathrm{~K}$. The $E-I$ curves that were measured at $76 \mathrm{~K}$ in self-field are also included in the figure and are indicated by open symbols. The critical current at $76 \mathrm{~K}$ in self-field corresponds to that at about $16 \mathrm{~T}$ and $4.2 \mathrm{~K}$. The resistive transition at low currents from which the contact resistance between cable terminals and tapes is determined is clearly visible in the $E-I$ characteristics that were measured with the voltage contacts on the terminals (squares). Such a resistive transition is not measured with the voltage contacts that were located on one of the tapes in the outer layer of the cable (circles).

The magnetic field dependence of $I_{\mathrm{c}}$ at $4.2 \mathrm{~K}$ of cable CORC-1, determined with the voltage contacts on the cable ends, is shown in figure 5 , together with $I_{\mathrm{c}}$ measured at $76 \mathrm{~K}$ in self-field. Unfortunately, the maximum current of the power supplies available at the time was $2000 \mathrm{~A}$, which 


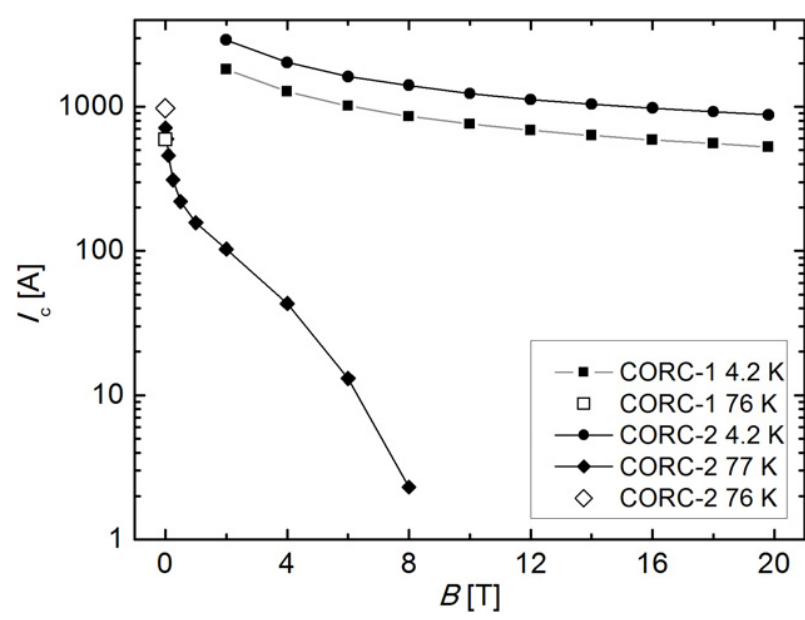

Figure 5. Magnetic field dependence of $I_{\mathrm{c}}$ for cable CORC-1 at $4.2 \mathrm{~K}$ and at $76 \mathrm{~K}$, and of cable CORC-2 at $4.2,76$ and $77 \mathrm{~K}$.

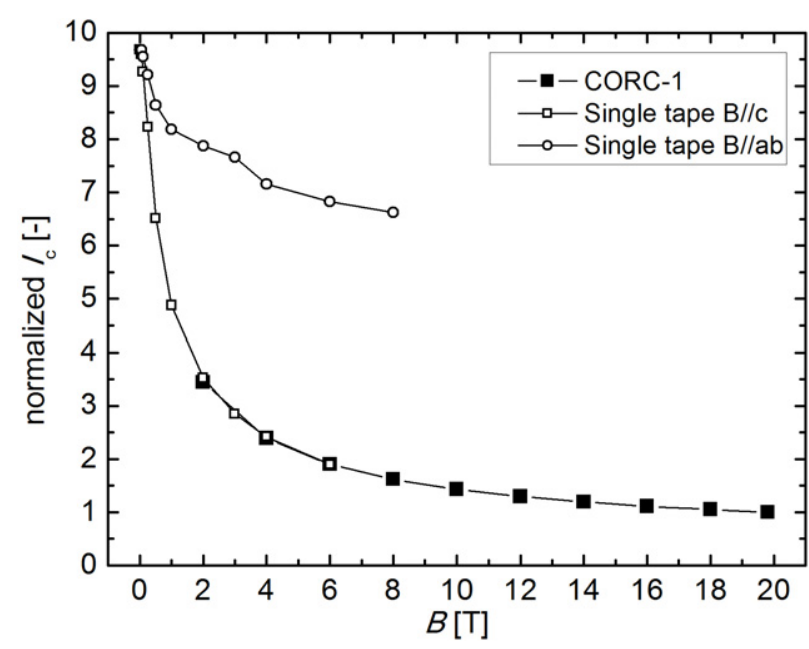

Figure 6. Magnetic field dependence of the normalized $I_{\mathrm{c}}$ at $4.2 \mathrm{~K}$ of cable CORC-1 and of a superconducting tape from a similar batch of ST coated conductors. The magnetic field dependence of $I_{\mathrm{c}}$ of the single tape is plotted for magnetic fields applied parallel to the $c$-axis and parallel to the $a b$-plane of the REBCO layer. The critical current of cable CORC-1 is normalized to its value at $19.8 \mathrm{~T}$, while the tape $I_{\mathrm{c}}$ for both field orientations is multiplied by a factor of 0.014 , such that its $I_{\mathrm{c}}$ at $6 \mathrm{~T}$ for field applied parallel to the $c$-axis corresponds to that of the cable at $6 \mathrm{~T}$.

prevented us from measuring $I_{\mathrm{c}}$ at magnetic fields below $2 \mathrm{~T}$. The self-field generated by the cable has not been taken into account, because it is much less than the applied magnetic field.

The magnetic field dependence for $I_{\mathrm{c}}$ of cable CORC-1 at $4.2 \mathrm{~K}$ for fields up to $19.8 \mathrm{~T}$ is compared in figure 6 to that of a single coated conductor from a similar batch for fields up to $8 \mathrm{~T}$. Both conductors in the cable and the individual coated conductor were from the standard type, which did not included advanced pinning centers. The magnetic field dependence of $I_{\mathrm{c}}$ for the single coated conductor was measured for magnetic fields applied parallel to the $c$-axis and for magnetic fields applied parallel to the $a b$-planes of the REBCO layer. The critical current of the

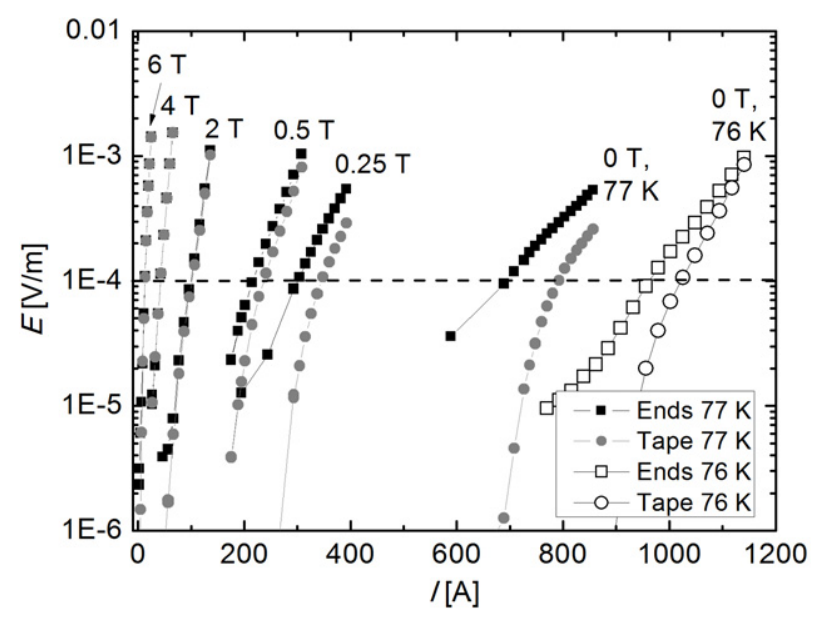

Figure 7. $E-I$ characteristics of cable CORC-2, as measured with two sets of voltage contacts. One set was located on the copper terminal (squares) and one set was located on one of the tapes in the outer layer of the cable (circles). All data were measured at $77 \mathrm{~K}$, except for the two curves that were measured at $76 \mathrm{~K}$ in self-field (open symbols). The dashed line indicates the electric field criterion of $1 \mu \mathrm{V} \mathrm{cm}^{-1}$.

cable is normalized to its value at $19.8 \mathrm{~T}$. For comparison, the $I_{\mathrm{c}}$ of the tape for field parallel to the $c$-axis $(=136 \mathrm{~A})$ is scaled to match the cable $I_{\mathrm{c}}$ at $6 \mathrm{~T}$, requiring multiplication by a factor of 0.014 . The normalized $I_{\mathrm{c}}$ for the cable coincides with that of the tape with field applied parallel to the $c$-axis over the range of 2-6 T, indicating that the performance of CORC cables is determined by the magnetic field component parallel to the $c$-axis of its tapes. This is expected because the magnetic field orientation experienced by each tape in a CORC cable varies over its length between the case of parallel to the $c$-axis and that of parallel to the $a b$-plane. The locations in each tape corresponding the lowest $I_{\mathrm{c}}$, which are those where the magnetic field is oriented along the $c$-axis, will determine the overall dissipation in each tape in the cable. Comparison of the cable $I_{\mathrm{c}}$ with the tape $I_{\mathrm{c}}$ in magnetic fields applied parallel to the $a b$-plane shows that the cable $I_{\mathrm{c}}$ at high field can potentially be raised by a factor of 4 through improvements of the flux pinning in these conductors that contain no enhanced pinning centers.

The $E-I$ characteristics of cable CORC- 2 were measured at NIST for $76 \mathrm{~K}$ in self-field before the cable was wound into a 1.5-turn loop. The same characteristics were measured as a function of magnetic field at $77 \mathrm{~K}$ at the NHMFL after the cable was wound into the loop (see figure 7). The voltages were measured with two sets of voltage contacts; one set was located on the copper cable terminals (squares) and one set was located on one of the tapes in the outer layer of the cable (circles). The overall contact resistance was about $25 \mathrm{n} \Omega$ at $76 \mathrm{~K}$. The $I_{\mathrm{c}}$ that was measured at the NHMFL at $77 \mathrm{~K}$ in self-field after the cable was wound into the 1.5-turn loop was only $714 \mathrm{~A}$, compared to $976 \mathrm{~A}$ at $76 \mathrm{~K}$ before it was wound into the loop. This large difference indicates that some damage to the cable occurred during winding because the expected critical current at $77 \mathrm{~K}$ is about $850 \mathrm{~A}$, assuming a reduction in $I_{\mathrm{c}}$ of about $15 \%$ when the temperature is raised from 76 to $77 \mathrm{~K}$. 


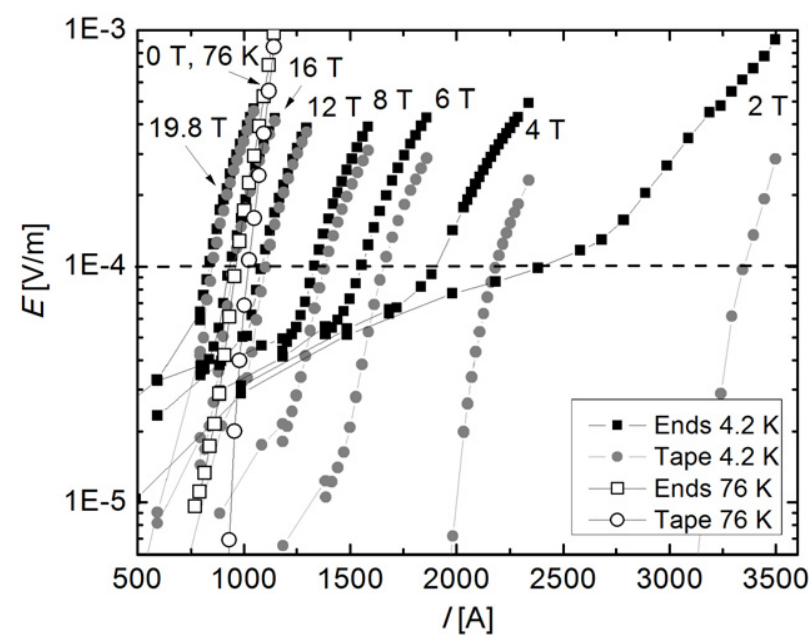

Figure 8. $E-I$ characteristics of cable CORC-2 as a function of magnetic field at $4.2 \mathrm{~K}$, determined with two sets of voltage contacts; one set was located on the copper terminal (squares) and one set was located on one of the tapes in the outer layer of the cable (circles). Data taken at $76 \mathrm{~K}$ in self-field are included in the figure (open symbols). The dashed line indicates the electric field criterion of $1 \mu \mathrm{V} \mathrm{cm}^{-1}$

The $E-I$ characteristics of cable CORC-2, that were measured as a function of magnetic field at $4.2 \mathrm{~K}$, are shown in figure 8. The critical current of the cable was $877 \mathrm{~A}$ at $19.8 \mathrm{~T}$, which corresponds to a $J_{\mathrm{e}}$ of $26 \mathrm{~A} \mathrm{~mm}^{-2}$ (see table 2). The overall contact resistance was about $15 \mathrm{n} \Omega$ at $4.2 \mathrm{~K}$. The critical current could not be determined for fields below $2 \mathrm{~T}$ because of the $3500 \mathrm{~A}$ current limit of the power supplies during the test of sample CORC-2. The magnetic field dependences of $I_{\mathrm{c}}$ for cable CORC-2 at $4.2 \mathrm{~K}$ and at $77 \mathrm{~K}$ are compared to those of cable CORC-1 in figure 5.

\subsection{Current distribution effects}

The minor damage that occurred in cable CORC-2 when it was wound into the $11 \mathrm{~cm}, 1.5$-turn loop resulted in an inhomogeneous current distribution between its tapes that is most pronounced at magnetic fields below $8 \mathrm{~T}$. The inhomogeneous current distribution is evident from the $E-I$ characteristics that are shown in figure 8 . The superconducting transition determined with the voltage contacts on the cable ends occurs at a much lower cable current compared with the transition, when measured on one of the tapes in the outer layer of the cable. Once it occurs, the superconducting transition of the particular tape occurs more rapidly than that of the overall cable, which is indicated by a relatively high $n$-value. The $n$-value of the superconducting tape increases from about 10 at high fields, where the current distribution is more homogeneous, to 23 at fields below $8 \mathrm{~T}$. The $n$-value of the cable that is determined with the voltage contacts on the terminals is in the range of 12-18 independent of magnetic field. The magnetic field dependence of $I_{\mathrm{c}}$ of cable CORC-2 that is shown in figure 9 also reveals the relatively large difference in $I_{\mathrm{c}}$ at fields below $8 \mathrm{~T}$ when determined with two different sets of voltage contacts. These measurements show

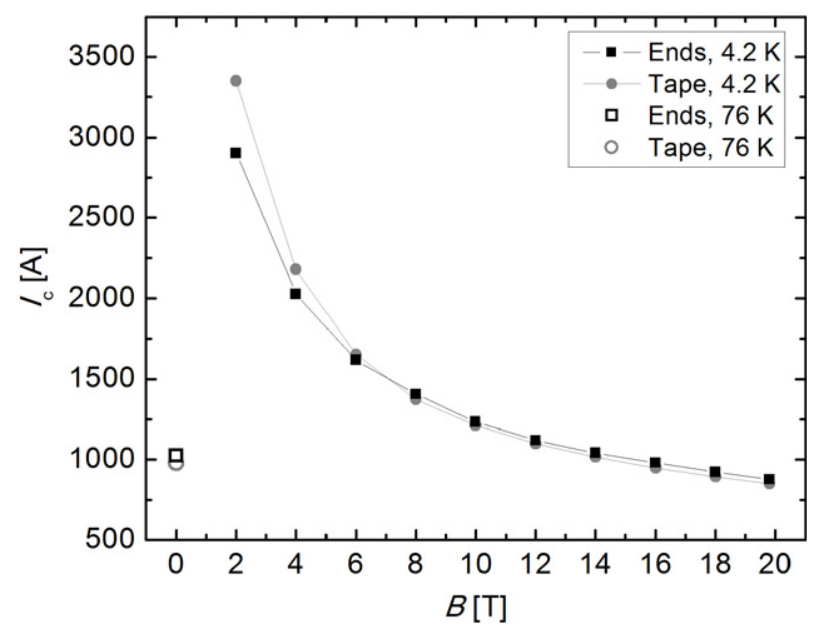

Figure 9. Magnetic field dependence of $I_{\mathrm{c}}$ of cable CORC-2 as determined with two sets of voltage contacts. Included in the figure are the critical currents of the cable at $76 \mathrm{~K}$ in self-field (open symbols)

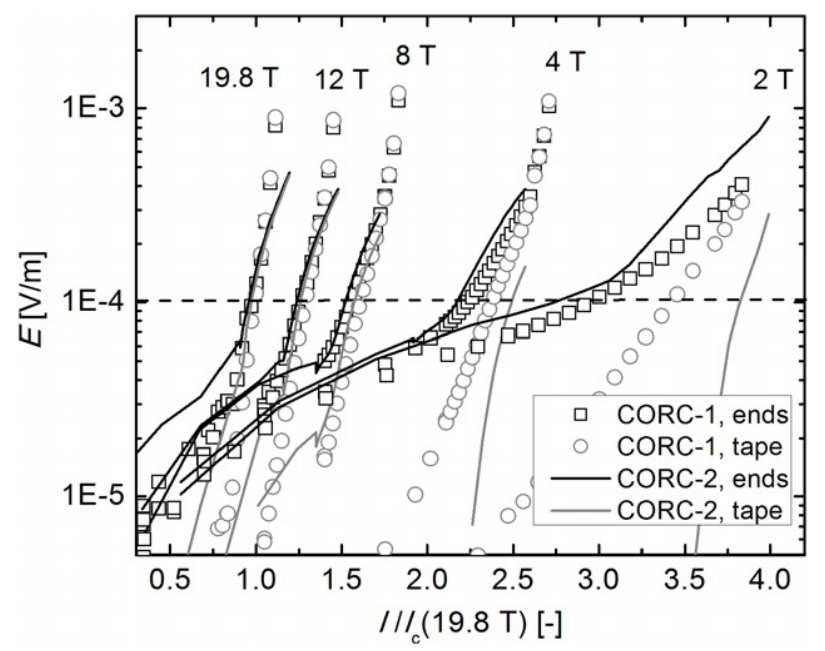

Figure 10. Electric field as a function of normalized current of cables CORC-1 and CORC-2 at different magnetic fields at $4.2 \mathrm{~K}$. The applied currents are normalized to their cable $I_{\mathrm{c}}$ values at an applied field of $19.8 \mathrm{~T}$ to allow a direct comparison between the two cables that have different overall critical currents. The dashed line indicates the electric field criterion of $1 \mu \mathrm{V} \mathrm{cm}-1$.

that the most reliable method to determine the overall cable $I_{\mathrm{c}}$ with a single tap is with the voltage contacts on the terminals, and not with one located on only one tape.

The inhomogeneous current distribution in cable CORC2 at magnetic fields below $8 \mathrm{~T}$ is also evident when the $E-I$ characteristics of the cable are compared with those from cable CORC-1, in which the current distribution is more homogeneous. The electric field of both cables, as measured with the voltage contacts on the copper terminals and on one of the outer tapes, is plotted in figure 10 as a function of normalized current for different magnetic fields. The electric fields that were measured with the voltage contacts on the cable terminals are comparable for both cables at all magnetic fields. On the other hand, the electric fields that were measured on one of the tapes in the outer layer of the 


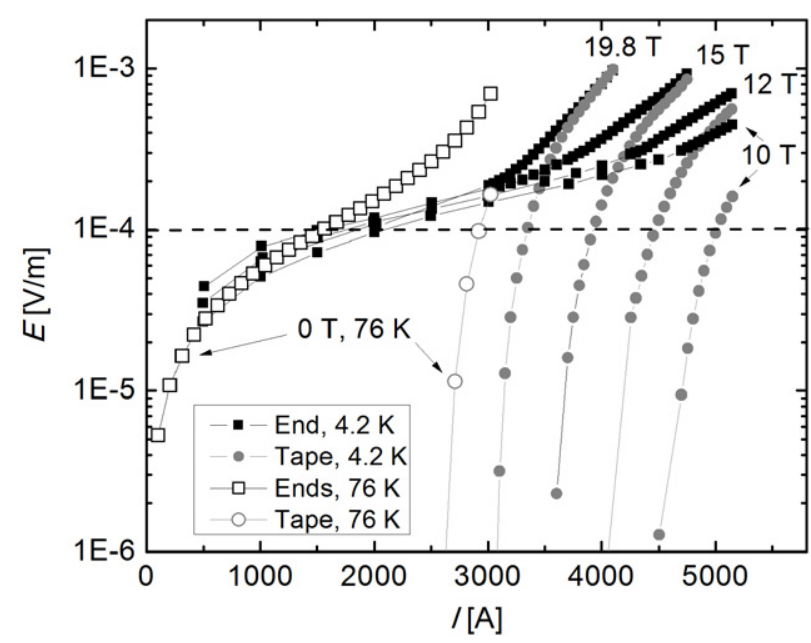

Figure 11. $E-I$ characteristics for cable CORC-3 at $76 \mathrm{~K}$ in self-field and at $4.2 \mathrm{~K}$ for magnetic fields ranging from 10 to $19.8 \mathrm{~T}$. One set of voltage contacts was located on the copper terminal (squares) and one set was located on one of the tapes in the outer layer of the cable (circles). The dashed line indicates the electric field criterion of $1 \mu \mathrm{V} \mathrm{cm}-1$.

cables show a large deviation between the two cables at fields below $8 \mathrm{~T}$. The overall cable electric field in cable CORC-2 reaches $1 \mu \mathrm{V} \mathrm{cm}^{-1}$ at a cable current of $2901 \mathrm{~A}$ at $2 \mathrm{~T}$, compared to $3350 \mathrm{~A}$ when the transition is measured on one of the tapes. Such a large deviation in the current, for which the superconducting transition occurs, was not measured in cable CORC-1, even at $2 \mathrm{~T}$, nor was it measured in sample CORC-2 at $76 \mathrm{~K}$ in self-field, before being wound into the loop (see figure 8 ). Therefore, we conclude that the current distribution in cable CORC-2 is inhomogeneous and that the inhomogeneous distribution is most likely caused by damage that occurred during winding of the cable into the $11 \mathrm{~cm}$ diameter loop.

\subsection{High-current CORC cable tests}

Cable CORC-3 was wound from 40 coated conductors to demonstrate the feasibility of a high cable $I_{\mathrm{c}}$ at high magnetic fields. A cable $I_{\mathrm{c}}$ of $2426 \mathrm{~A}$ was measured at $76 \mathrm{~K}$ after the cable was wound into a loop of $11 \mathrm{~cm}$ diameter. A critical current of $3327 \mathrm{~A}$ was measured at $4.2 \mathrm{~K}$ and $19.8 \mathrm{~T}$, which corresponds to a $J_{\mathrm{e}}$ of $76 \mathrm{~A} \mathrm{~mm}^{-2}$ and a $J_{\mathrm{w}}$ of $60 \mathrm{~A} \mathrm{~mm}^{-2}$. The cable current was raised to a quench current of $4101 \mathrm{~A}$ at $19.8 \mathrm{~T}$. The $E-I$ characteristics of cable CORC-3 are shown in figure 11 for magnetic fields between 10 and $19.8 \mathrm{~T}$ at $4.2 \mathrm{~K}$, and at $76 \mathrm{~K}$ in self-field. They were measured with two pairs of voltage contacts, one pair located on the cable terminals (squares) and one pair located on one of the tapes in the outer layer (circles). The total contact resistance between the cable terminals and the tapes was about $60 \mathrm{n} \Omega$ at $76 \mathrm{~K}$ and about $25 \mathrm{n} \Omega$ at $4.2 \mathrm{~K}$.

The critical current of cable CORC-3 was measured for fields as low as $10 \mathrm{~T}$, at which field the sample current exceeded $5000 \mathrm{~A}$, the limit of our setup at the time. Figure 12 shows the magnet field dependence of $I_{\mathrm{c}}$ as determined with

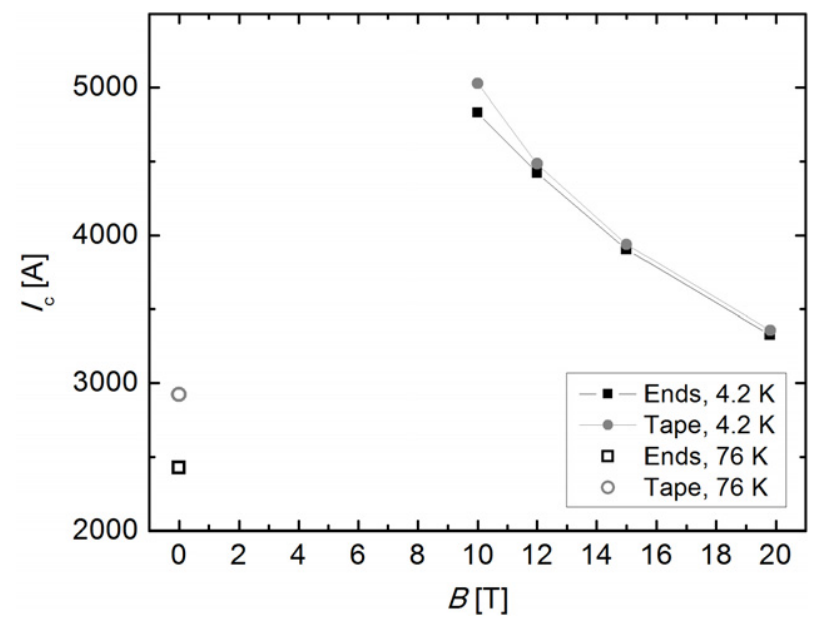

Figure 12. Magnetic field dependence of $I_{\mathrm{c}}$ of cable CORC-3 at $4.2 \mathrm{~K}$, determined with two sets of voltage contacts. One set was located on the copper terminal (squares) and one set was located on one of the tapes in the outer layer of the cable (circles). The cable $I_{\mathrm{c}} \mathrm{s}$ at $76 \mathrm{~K}$ in self-field are included (open symbols).

both sets of voltage contacts. The cable $I_{\mathrm{c}}$ at $76 \mathrm{~K}$ in self-field is also included in the figure. The AP coated conductors used in part to construct cable CORC-3 resulted in a much higher in-field performance at $4.2 \mathrm{~K}$, compared to that of cables CORC-1 and CORC-2, which contained only ST coated conductors. As a result, the $I_{\mathrm{c}}$ of cable CORC-3 at $76 \mathrm{~K}$ in self-field corresponds to $I_{\mathrm{c}}$ at $4.2 \mathrm{~K}$ for a field exceeding $19.8 \mathrm{~T}$, compared to about $16 \mathrm{~T}$ for sample CORC-1 and about $15 \mathrm{~T}$ for cable CORC-2. The advanced pinning in most of the conductors of cable CORC-3 has resulted in an enhancement of $I_{\mathrm{c}}$ at $19.8 \mathrm{~T}$ of at least $50 \%$, compared to the standard conductors used in cables CORC-1 and CORC-2, when compared to their $I_{\mathrm{c}} \mathrm{s}$ at $76 \mathrm{~K}$ in self-field.

Cable CORC-4 was tested at $4.2 \mathrm{~K}$ in a background field of $19 \mathrm{~T}$. The $E-I$ characteristics for the measurement are shown in figure 13 . The cable had a record critical current of $5021 \mathrm{~A}$, or a $J_{\mathrm{e}}$ of $114 \mathrm{~A} \mathrm{~mm}^{-2}$ at $19 \mathrm{~T}$, as determined from the voltage contacts on the cable terminals. The contact resistance between the superconducting tapes and both cable terminals was $23 \mathrm{n} \Omega$. The maximum sample current was $6116 \mathrm{~A}$, at which the sample quenched. The critical current could not be measured at lower magnetic fields, or at $76 \mathrm{~K}$, because of the current limit of our setup at the time.

\subsection{Magnet wound from CORC cable}

The small magnet that was wound from cable CORC-5 was tested at $4.2 \mathrm{~K}$ in background fields ranging from 12 to $19.8 \mathrm{~T}$. This magnet is the first HTS cable magnet tested in a background field of this magnitude. The $E-I$ characteristics of the coil measured in a background field of $12 \mathrm{~T}$, with four different sets of voltage contacts, are shown in figure 14(a). The critical current determined with the contacts on the terminals was $2657 \mathrm{~A}$ at $12 \mathrm{~T}$. The voltage drop at a cable current of about $1000 \mathrm{~A}$, as measured with three voltage pairs, indicates a redistribution of the current within the cable. 


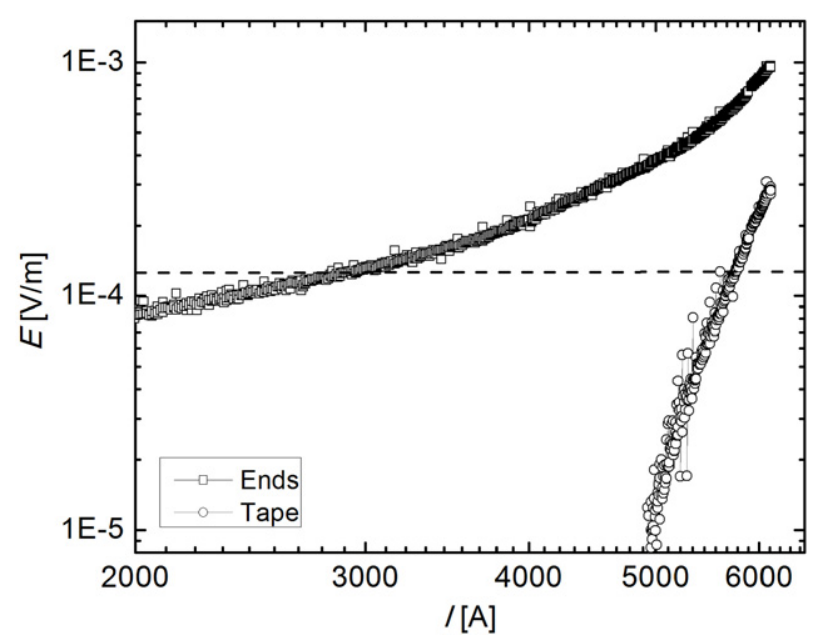

Figure 13. $E-I$ characteristics for cable CORC-4 at $4.2 \mathrm{~K}$ and a magnetic field of $19 \mathrm{~T}$. One set of voltage contacts was located on the copper terminal (squares) and one set was located on one of the tapes in the outer layer of the cable (circles). The dashed line indicates the electric field criterion of $1 \mu \mathrm{V} \mathrm{cm}^{-1}$.

The voltage contact pair located over the inner layer of the coil (open circles) does not measure such a voltage drop. The current redistribution is most likely the result of damage near the end of the top winding in the outer layer of the magnet, that occurred during winding, where a small kink in some of the tapes in the cable was visible. The three pairs of voltage contacts, that show the voltage redistribution signature, are all located over the damaged cable section. The current redistribution is less apparent in a background field of $19.8 \mathrm{~T}$ (see figure 14(b)). The magnetic field that was generated by the magnet $B_{\text {self }}$ was measured at the magnet axis with a Hall probe and was $0.2 \mathrm{~T}$ at a cable current of about $2000 \mathrm{~A}$, resulting in a total field of $20 \mathrm{~T}$. The magnetic field of the magnet, as a function of current, is included in figures 14(a) and (b), indicating a linear dependence with a slope of $0.1 \mathrm{mT} \mathrm{A}^{-1}$. The critical current of the magnet at a total field of $20 \mathrm{~T}$ was $1966 \mathrm{~A}$, while the $I_{\mathrm{c}} \mathrm{s}$ of the inner and outer layers were $2014 \mathrm{~A}$ and $1916 \mathrm{~A}$, respectively. The magnet $I_{\mathrm{c}}$ of $1966 \mathrm{~A}$ corresponds to a $J_{\mathrm{e}}$ of $51 \mathrm{~A} \mathrm{~mm}^{-2}$ and a $J_{\mathrm{w}}$ of $40 \mathrm{~A} \mathrm{~mm}^{-2}$ at $4.2 \mathrm{~K}$ and $20 \mathrm{~T}$.

The critical current of the total magnet and its inner and outer layers was measured at different magnetic fields as low as $12 \mathrm{~T}$ (see figure 15). The overall $I_{\mathrm{c}}$ in the magnet is determined mainly by the outer layer that contains the damaged section. At the time, the current supplies available were limited to a maximum current of $3500 \mathrm{~A}$, which was insufficient to determine $I_{\mathrm{c}}$ at fields below $12 \mathrm{~T}$. A maximum current of $3500 \mathrm{~A}$ was applied to sample CORC-5 at $4.2 \mathrm{~K}$ in self-field, during which it generated a field of $350 \mathrm{mT}$ at the magnet axis.

A comparison with LTS cables that operate at fields between 13 and $15.3 \mathrm{~T}$ shows that cable CORC-3 already exceeds their performances with respect to $J_{\mathrm{w}}$ (see table 2). These magnets could potentially operate at a temperature of about $20 \mathrm{~K}$ when constructed from a CORC cable. For instance, $J_{\mathrm{w}}$ of $89 \mathrm{~A} \mathrm{~mm}^{-2}$ at $19 \mathrm{~T}$ and $4.2 \mathrm{~K}$ in CORC-3
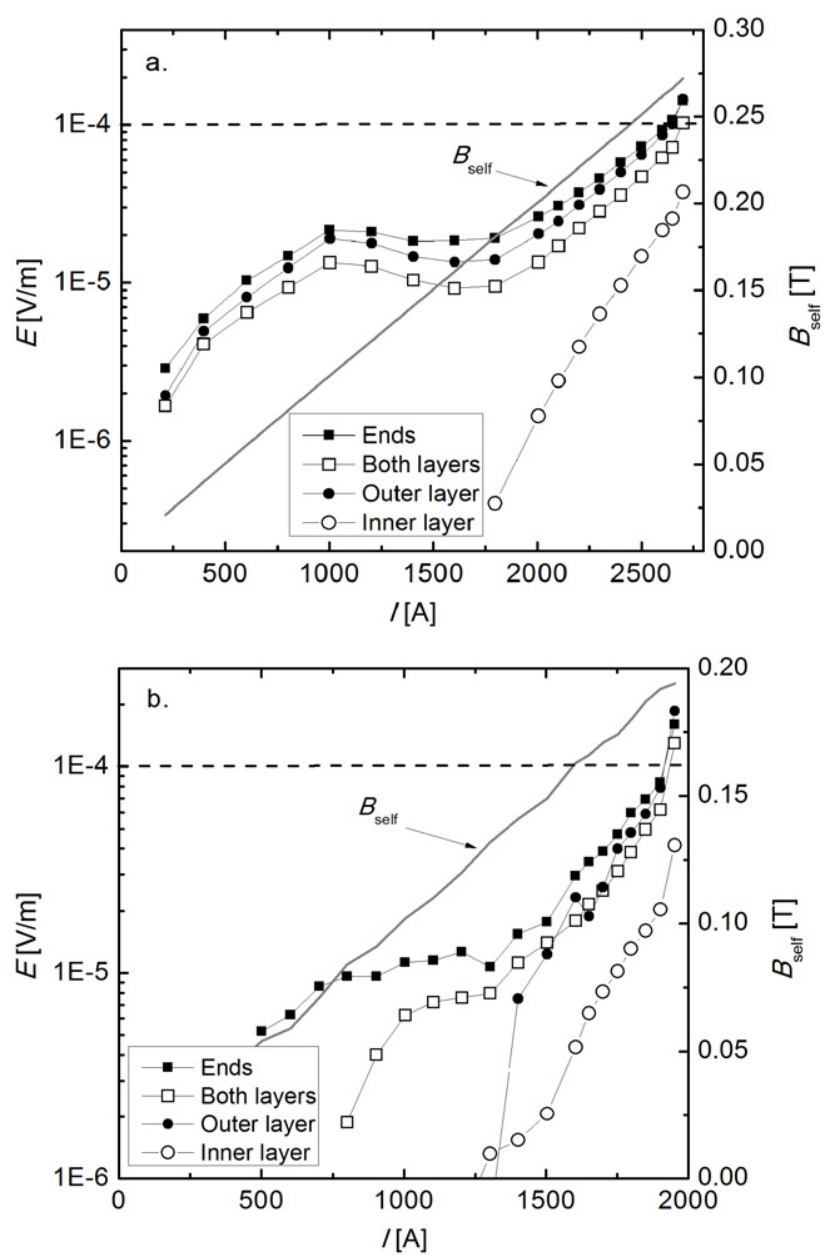

Figure 14. (a) $E-I$ characteristics of the magnet wound from cable CORC-5 at $4.2 \mathrm{~K}$ in a background field of $12 \mathrm{~T}$. (b) $E-I$ characteristics at $4.2 \mathrm{~K}$ in a background field of $19.8 \mathrm{~T}$. Four sets of voltage contacts were used in the measurements, as indicated in the figure. Included in both figures is the measured magnetic field generated by the coil. The dashed line indicates the electric field criterion of $1 \mu \mathrm{V} \mathrm{cm}^{-1}$.

is expected to correlate to about $74 \mathrm{~A} \mathrm{~mm}^{-2}$ at $12 \mathrm{~T}$ and $20 \mathrm{~K}$ [23], which greatly exceeds $J_{\mathrm{w}}$ of the ITER Central Solenoid. Additionally, the performance of CORC cables at $20 \mathrm{~T}$ and $4.2 \mathrm{~K}$ could potentially be raised towards a $J_{\mathrm{e}}$ of 200-600 A mm $\mathrm{m}^{-2}$ by reducing the thickness of the substrate of the tapes and by raising the conductor in-field $I_{\mathrm{c}}$ through an increase in thickness of the REBCO layer and through further improvement of its high-field pinning performance.

The measurements demonstrate the feasibility of operating CORC cables at currents that exceed $5000 \mathrm{~A}$ in magnetic fields of $19 \mathrm{~T}$. The results also show a clear path to further enhance the in-field performance of CORC cables towards very high $J_{\mathrm{e}} \mathrm{s}$ that are needed in, for instance, accelerator magnets.

\section{Conclusions}

We successfully performed the first measurements of hightemperature superconducting cables in background fields as 


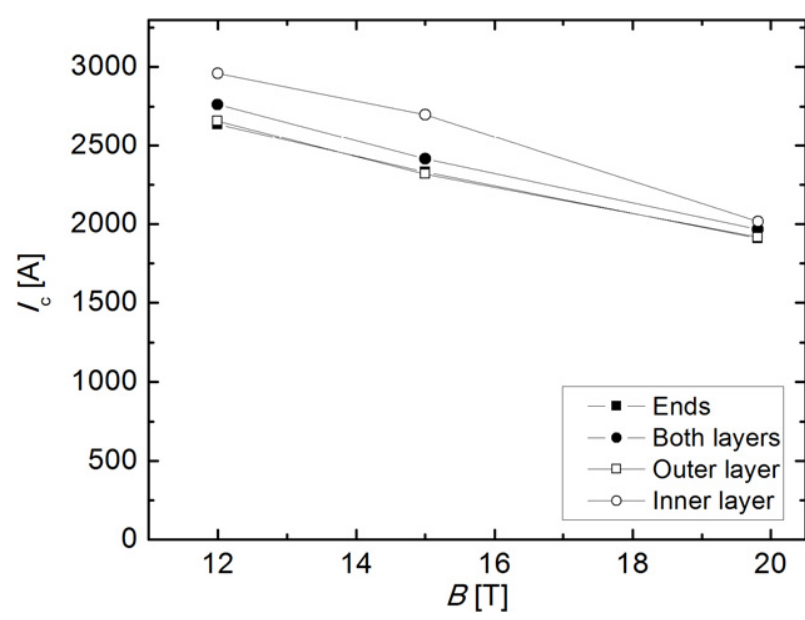

Figure 15. Magnetic field dependence of $I_{\mathrm{c}}$ of the magnet wound from cable CORC-5 at $4.2 \mathrm{~K}$ for both individual magnet layers, and for both layers combined.

high as $20 \mathrm{~T}$. Several conductor on round core cables were tested, demonstrating a critical current as high as $5021 \mathrm{~A}$ at $19 \mathrm{~T}$ and $4.2 \mathrm{~K}$, which corresponds to an engineering current density of $114 \mathrm{~A} \mathrm{~mm}^{-2}$. We performed the first measurements of a magnet wound from HTS cables at a total magnetic field of $20 \mathrm{~T}$, for which it had a critical current of almost 2000 A was demonstrated. The results demonstrate the feasibility of HTS CORC cables for low-inductance, high-field magnet applications. A comparison shows that electrical performance of some of the HTS CORC cables already exceed the performance of existing LTS cables that are currently being operated or developed. Magnets such as the ITER Central Solenoid, or the LTS outsert of the $45 \mathrm{~T}$ hybrid magnet at the NHMFL, could potentially be operated at higher magnetic fields, or at temperatures exceeding $20 \mathrm{~K}$ when constructed from HTS CORC cables.

\section{Acknowledgments}

This work was in part supported by the US Department of Energy under agreement numbers DE-AI05-98OR22652, DE-SC0007891, and DE-SC0007660. A portion of this work was performed at the National High Magnetic Field Laboratory, which is supported by National Science Foundation Cooperative Agreement number DMR-0654118, the State of Florida, and the US Department of Energy. Certain commercial materials are referred to in this paper to foster better understanding. Such identification implies neither recommendation nor endorsement by NIST, nor that the materials identified are necessarily the best available for the purpose.

\section{References}

[1] Larbalestier D C, Gurevich A, Feldmann D M and Polyanskii A A 2001 Nature 414 368-77

[2] Gupta R et al 2011 IEEE Trans. Appl. Supercond. 21 1884-7

[3] Bromberg L, Hashizume H, Ito S, Minervini J V and Yanagi N 2011 Fusion Sci. Technol. 60 635-42

[4] www.bnl.gov/newsroom/news.php?a=11174

[5] Weijers H W et al 2010 IEEE Trans. Appl. Supercond. 20 576-82

[6] Schultz J H, Antaya T, Feng J, Gung C Y, Martovetsky N, Minervini J V, Michael P, Radovinsky A and Titus P 2006 The ITER central solenoid 21st IEEE/NPSS Symp. on Fusion Engineering-SOFE 05 pp 142-5

[7] Scanlan R M, Dietderich D R, Higley H C, Marken K R, Motowidlo L R, Sokolowski R and Hasegawa T 1999 IEEE Trans. Appl. Supercond. 9 130-3

[8] Godeke A et al 2010 Supercond. Sci. Technol. 23034022

[9] Kametani F et al 2011 Supercond. Sci. Technol. 24075009

[10] Kajbafvala A, Nachtrab W, Lu X F, Hunte F, Liu X, Cheggour N, Wong T and Schwartz J 2012 IEEE Trans. Appl. Supercond. 228400210

[11] Goldacker W, Nast R, Kotzyba G, Schlachter S I, Frank A, Ringsdorf B, Schmidt C and Komarek P 2006 J. Phys. Conf. Ser. 43 901-4

[12] Goldacker W, Frank A, Kudymow A, Heller R, Kling A, Terzieva S and Schmidt C 2009 Supercond. Sci. Technol. 22034003

[13] Takayasu M, Chiesa L, Bromberg L and Minervini J V 2012 Supercond. Sci. Technol. 25014011

[14] Takayasu M, Minervini J V, Bromberg L, Rudziak M K and Wong T 2012 Advances in Cryogenic Engineering (AIP Conf. Proc. vol 1435) vol 58, ed U Balachandran (Melville, NY: American Institute of Physics) pp 273-80

[15] van der Laan D C, Dhallé M, van Eck H J N, Metz A, ten Haken B, ten Kate H H J, Naveira L M, Davidson M W and Schwartz J 2005 Appl. Phys. Lett. 86032512

[16] van der Laan D C, Abraimov D, Polyanskii A A, Larbalestier D C, Douglas J F, Semerad R and Bauer M 2011 Supercond. Sci. Technol. 24115010

[17] www.advancedconductor.com

[18] van der Laan D C 2009 Supercond. Sci. Technol. 22065013

[19] van der Laan D C, Lu X F and Goodrich L F 2011 Supercond. Sci. Technol. 24042001

[20] van der Laan D C and Ekin J W 2007 Appl. Phys. Lett. 90052506

[21] van der Laan D C, Goodrich L F and Haugan T J 2012 Supercond. Sci. Technol. 25014003

[22] Miller J R 2003 IEEE Trans. Appl. Supercond. 13 1385-90

[23] Xu A, Braccini V, Jaroszynski J, Xin Y and Larbalestier D C 2012 Phys. Rev. B 86115416 